\title{
Acute Genital Peritonitis in Brazzaville, Congo
}

\author{
Massamba Miabaou Didace ${ }^{1^{*}}$, Mbongo Jean Alfred ${ }^{2}$, Note Madzélé Murielle ${ }^{1}$, \\ Motoula Latou Noé1, Itoua Clautaire ${ }^{2}$, Massamba Alphonse ${ }^{3}$
}

${ }^{1}$ Digestive Surgery Department, Brazzaville University Hospital, Brazzaville, Congo

${ }^{2}$ Gynecology-Obstetrics Department, Brazzaville University Hospital, Brazzaville, Congo

${ }^{3}$ Laboratory of Numerical Analysis, Computer Science and Applications (LANIA), Faculty of Sciences and Technology,

Marien Ngouabi University, Brazzaville, Congo

Email: *didamassamba@gmail.com

How to cite this paper: Didace, M.M., Alfred, M.J., Murielle, N.M., Noé, M.L., Clautaire, I. and Alphonse, M. (2019) Acute Genital Peritonitis in Brazzaville, Congo. Surgical Science, 10, 368-376. https://doi.org/10.4236/ss.2019.1010041

Received: September 14, 2019

Accepted: October 22, 2019

Published: October 25, 2019

Copyright $\odot 2019$ by author(s) and Scientific Research Publishing Inc. This work is licensed under the Creative Commons Attribution International License (CC BY 4.0).

http://creativecommons.org/licenses/by/4.0/

(c) (i) Open Access

\begin{abstract}
Genital peritonitis is rare in daily surgical practice in Congo-Brazzaville. Clandestine abortions are incriminated. The purpose of the study is to analyze the epidemiological, etiological, diagnostic and therapeutic aspects of genital peritonitis. A retrospective and case series study was realized in departments of Digestive Surgery and Gynecology-Obstetrics of the University Hospital of Brazzaville. The inclusion criteria for the diagnosis of peritonitis were abdominal pain, fever, transit disturbances and signs of peritoneal irritation. The parameters studied were: age, etiological circumstances, anatomical lesions, type of surgical treatment and evolution. During the study period (July 1, 2015-December 31, 2017), 306 patients were admitted to both departments for acute generalized peritonitis. Among them, a genital cause was incriminated in 18 (5.9\%) patients. The mean age was $27.6 \pm 3.1$ years. At the parity and gestational level, $93 \%$ of patients had at least two pregnancies, but not more than the second trimester. In addition, $50 \%$ of the patients had an induced miscarriage, due to uterine and intestinal lesions. Induced miscarriages accounted for half of etiological circumstances. Physical examination of the abdomen revealed abdominal contracture in $61.1 \%$ of cases. Main visceral lesions were uterine perforation (55.5\%) followed by rupture of tubo-ovarian abscess (38.9\%). The operative follow-up was simple in $83.33 \%$ of cases. In conclusion, genital peritonitis remains unfrequented. Median laparotomy has been the main therapeutic approach in our context where emergency laparoscopic surgery is not yet common.
\end{abstract}

\section{Keywords}

Peritonitis, Abortion, Uterine Perforation 


\section{Introduction}

Acute peritonitis is the peritoneum inflammation by septic inoculation, usually from an intraperitoneal organ and more rarely after general contamination [1]. This inflammation is of two kinds: the first results from haematogenous spread or iatrogenic contamination of the abdomen without a defect of the gastrointestinal tract; on the other hand, the second is due to a direct contamination of the peritoneum by spillage from the gastrointestinal or urogenital tracts or their associated solid organs [2] [3]. More recently, a third order has been added: tertiary peritonitis, which refers to secondary peritonitis that persists for more than 48 hours after an attempt to control the surgical source [4]. It can be localized or generalized.

Genital origin is quoted when the inflammation of the cavity follows a uterine, salping or ovarian cause [5]. Genital peritonitis is rare, its frequency varies from one study to another and according to the environment [6]. Clinical symptomatology is crude and often misleading. This explains the diagnostic difficulties and the delay in treatment, especially nowadays because of clandestine abortions in sub-Saharan African countries. These, unauthorized, are responsible for significant maternal mortality [7] because of the often polymorphous and misleading symptomatology. The principles of surgical management of secondary peritonitis have changed little since the 1900s: eliminating the septic focus, removing necrotic tissue and draining purulent material [2].

The purpose of this study was to analyze the epidemiological, etiological, diagnostic and therapeutic aspects of genital peritonitis at the Brazzaville University Hospital.

\section{Material and Methods}

\subsection{Study Design}

A retrospective and case series study was conducted from July 1, 2015 to December 31, 2017 in the departments of Digestive Surgery and Gynecology-Obstetrics of the Brazzaville University Hospital, Congo. The relevant information was taken from the files respectively in both services.

\subsection{Selection Criteria of Patients}

The inclusion criteria used for the diagnosis of peritonitis were abdominal pain, fever with a temperature greater than or equal to $38^{\circ} \mathrm{C}$, transit disorders (diarrhea, vomiting, stopping of faeces and gas) and signs of peritoneal irritation (defense, contracture) in a context of amenorrhea. In most cases, the context of occurrence of peritonitis was suggestive and sometimes confessed, including the notion of endo-uterine maneuver and abortion. The confirmation of pelviperitonitis or tuberculous peritonitis diagnosis in patients during the file review was an exclusion criterion. The National Ethic Committee of Health and Sciences Research of Congo approved data collection. The board waived the need for informed consent, as this was a retrospective study. 


\subsection{Variables}

The paraclinical examinations used abdominal X-ray, abdominal ultrasound and abdominal CT scan.

All patients underwent emergency exploratory laparotomy. Subsequently, they were admitted to the gynecology-obstetrics department when the found lesion was genital or in the department of Digestive Surgery when a digestive lesion revealed. Patients were divided into three age groups: 18 - 27 years old; 28 37 years old and 38 - 47 years old.

The parameters studied were: age, etiological circumstances, anatomical lesions, type of surgical treatment and surgical outcome.

\subsection{Statistical Analysis}

Qualitative data are expressed as effective and percentage, quantitative data as mean \pm SD. The comparison between several percentages and the difference between the three age groups were performed using $\mathrm{S}$ test of Sokal and Rolhf [8]. Chi square test was used to assess the relationship between severity and outcome. The severity was appreciated by the occurrence of septic shock state and hypovolemia. $\mathrm{p}<0.05$ defined the level of statistical significance. All data has been entered from the Epi-Info 2000 version 6.0 software. Data grouping and statistical analysis were performed using SPSS software version 23.0 at the Laboratory of Numerical Analysis, Computer Engineering and Applications, Faculty of Sciences and Technology, Marien Ngouabi University.

\section{Results}

\subsection{Epidemiological Aspects}

During the study period, 306 patients were admitted to both departments for acute generalized peritonitis. Among them, a genital cause was incriminated in 18 patients, as a frequency of $5.9 \%$.

Data for age for patients sample are indicated in Table 1.

More than half of the patients $(\mathrm{n}=14,77.7 \%, \mathrm{p}=0.035)$ were between 19 and 37 years of age. The mean age was $27.6 \pm 3.1$ years (range: $18-41$ years). Of the marital status, 12 (66.7\%) were single, 4 were common-law, and two were married. Their level of education did not exceed the secondary level of high school. At the parity and gestational level, $93 \%$ of patients $(n=17)$ had at least two pregnancies, but not more than the second trimester. In addition, $50 \%$ of the patients $(n=9)$ had an induced miscarriage, due to uterine and intestinal lesions.

Table 1. Distribution of patients as function as age.

\begin{tabular}{ccc}
\hline Age (years) & $\mathbf{n}$ & $\%$ \\
\hline $18-27$ & 8 & 44.4 \\
$28-37$ & 6 & 33.3 \\
$38-47$ & 4 & 22.3 \\
\hline
\end{tabular}




\subsection{Etiologies and Field}

The analysis of etiological circumstances revealed a frequency of $50 \%$ of induced miscarriages, which were the main causes of generalized acute peritonitis (Table 2). These were followed by tubo-ovarian abscesses (33.3\%). Immunosuppression to HIV accounted for only $11.1 \%$ of cases $(n=2)$.

\subsection{Clinical and Paraclinical Aspects}

Anamnestic data indicated that at admission, all patients presented abdominal pain and fever. In addition, after the clinical examination an impairment of the general condition was revealed in 8 patients (44.4\%). Genital bleeding was observed in nine patients $(50 \%)$, associated to miscarriage and uterine rupture in one patient. Abdominal physical examination revealed an abdominal distension, with generalized defense in 7 patients (38.9\%); abdominal contracture was found in $61.1 \%$ of cases ( $\mathrm{n}=11, \mathrm{p}=0.041)$.

All patients underwent emergency abdominal ultrasound. In contrast, computed tomography was performed in only 3 patients, that revealed an intraperitoneal effusion and a uterine lesion.

\subsection{Therapeutic Aspects and Injury Assessment}

All patients underwent exploratory laparotomy during which various visceral lesions were found (Table 3). First, 55.5\% (10 cases) of the patients had uterine perforation, followed by rupture of tubo-ovarian abscess (7 cases, 38.9\%). The letting of threads suture constituted only one case. Antibiotic therapy preceding and completing the surgical procedure targeted aerobic and anaerobic germs. Metronidazole-associated ceftriaxone was chosen in all patients for 7 - 14 days.

This laparotomy made it possible to perform the surgical procedures reported in Table 4.

Table 2. Data of main etiologies.

\begin{tabular}{ccc}
\hline Etiologies & $\mathbf{n}$ & $\%$ \\
\hline Endo-uterine maneuvers & 10 & $55.5^{*}$ \\
Rupture of tubo-ovarian abscess & 6 & 33.3 \\
Rupture of an ovarian cyst & 2 & 11.2 \\
Total & 18 & 100
\end{tabular}

${ }^{*} \mathrm{p}<0.05$.

Table 3. Main anatomic lesions observed.

\begin{tabular}{ccc}
\hline Types of lesions & $\mathbf{n}$ & $\%$ \\
\hline Rupture of tubo-ovarian abscess & 7 & 38.9 \\
Uterine perforation & 5 & 27.8 \\
Uterine and sigmoidal perforation & 3 & 13.7 \\
Uterine and ileal perforation & 2 & 11.1 \\
Letting go of threads suture & 1 & 8.5 \\
Total & 18 & 100 \\
\hline
\end{tabular}


Table 4. Surgical treatment techniques.

\begin{tabular}{cl}
\hline Surgical gesture & $\mathbf{n}$ \\
\hline Hystérorraphie & 9 \\
Adnexectomy & 6 \\
Colostomy & 3 \\
Ileostomy & 2 \\
Hysterectomy & 2 \\
\hline
\end{tabular}

\subsection{Biological Aspects}

Only 12 patients benefited from bacteriological analysis of pus. Echerichia coli and Staphylococcus aureus were the most common germs.

\subsection{Evolution}

Mean duration of hospitalization was 9.48 days. Operative follow-up was simple in $83.3 \%$ of cases $(n=15)$ and complicated in $16.7 \%$ of cases $(n=3)$. These complications were made of parietal suppurations. Two deaths were observed, due to septic shock (11.1\% of cases).

\section{Discussion}

\subsection{Epidemiological Aspects}

Peritonitis of genital origin is uncommon surgical pathology. In our study, frequency is $5.9 \%$. However, this frequency is variously appreciated according to the authors. Harouna in Niger [9], Ouangré in Burkina Faso [10], Kanté in Mali [11] and Ngo Nonga in Cameroon [12] report respectively 6\%, 3.2\% and 12.5\% and $9 \%$.

The frequency of peritonitis of genital origin is clearly decreasing at the Brazzaville University Hospital compared to the Iloki et al. [13] study in 1997 which recorded $10.86 \%$.

The epidemiological profile of patients with genital peritonitis reveals that they are young, low socio-economic and intellectual, often single or common-law.

\subsection{Etiological Aspects}

In our study, peritonitis is seen in two patients with HIV immunodepression. Indeed, HIV lowers immunity and exposes to infection. In the context of genital peritonitis dominated by abortions, it is legal to routinely make HIV serology for screening for early management in case of positivity. Peritonitis by uterine perforation was found in half of our patients. Indeed, it remains a frequent complication of clandestine abortions [13] [14]. This perforation is often associated with small bowel or colon damage [15] [16]. The practice of voluntary termination of pregnancy in hiding by a staff unqualified and in the most often septic 
conditions justifies the spread peritoneal microbial. This seeding is all the more important when uterine perforation is associated with hail or colonic perforation.

During abortions, intestinal lesions are relatively common and increasingly more reported [15] [16] [17]. Most often, the damaged intestinal segment is discovered during laparatomy for post-abortion peritonitis [18] [19]. Sometimes, the damaged intestinal segment is externalized to the vulva [20]. The socio-professional distribution of women who abort shows that those who do not have students, are most exposed to the various complications peritonitis.

\subsection{Clinical and Para-Clinical Aspects}

Like all peritonitis, peritonitis of gynecological origin translates clinically by peritoneal syndrome found in all patients with pain abdominal pain and peritoneal irritation resulting from a defense or abdominal contracture. Given the delay in consultation, these patients most often are presented at the advanced stage of peritonitis associated with septic shock.

Not all patients received bacteriological sampling because of the insufficiency of the technical equipment in the laboratory. Nevertheless, two main germs could be isolated including Echerichia coli and Staphylococcus aureus. Severity of peritonitis is related to the effects of a synergistic aerobic-anaerobic association and the pathogenic role of Enterobacteria type Echerichia coli [15].

\subsection{Therapeutic Aspects}

For all our patients, median laparotomy was the main approach to the cavity peritoneal while under other skins, laparoscopic surgery is supplanting surgery conventional. The laparotomy nevertheless made it possible to assess the lesions and to decide an adapted therapeutic attitude.

The attitude of proposing drainage by posterior colpotomy carried out by some authors [14] regardless of the type of peritonitis seems dangerous for future vital and functional of the patients. Most authors agree our approach [21] [22] [23].

Antibiotic therapy for surgery is fundamental and essential in the treatment of peritonitis in general [24] and particularly genital peritonitis. It must be broad spectrum. The authors agree that cefotaxime and cephalosporins are the probabilistic treatment of choice [25] [26] [27] [28].

\subsection{Evolution and Outcome}

Parietal suppuration is the main postoperative complication as most peritonitis [8] [9] [11] [29].

Mortality is still high because of the delay in surgical management of these peritonitis since the majority of patients in almost total deprivation, we are referred to peripheral health centers. The installation of septic shock state contributes poor prognosis especially during stercoral peritonitis. 


\subsection{Limits of the Study}

The reduced number of the sample is justified by the rarity of this pathology but may constitute a bias in the comparison of the results. The reduced number of the sample is justified by the rarity of this pathology but can constitute a bias in the comparison of the results. Moreover, because of the high cost of additional examinations, all patients have not benefited morphological investigations (Scanner, MRI, etc.). The genital etiology of peritonitis was only found during laparotomy.

\section{Conclusion}

Peritonitis of genital origin remains unfrequented surgical emergencies. Their etiologies are dominated by abortive uterine perforations associated or not with a small bowel or colon lesion. Clinical translation is identical to all peritonitis with existence of peritoneal syndrome. The treatment remains surgical. Median laparotomy was the main route of approach in our context where emergency laparoscopic surgery is not yet common. Mortality remains high due to association with septic shock.

\section{Conflicts of Interest}

The authors declare no conflicts of interest regarding the publication of this paper.

\section{References}

[1] Aubert, F. and Guittart, P. (1995) Essentiel médical de poche. 2nd Edition, Editions Marketing/Ellipse, Paris.

[2] Ross, J.T., Matthay, M.A. and Harris, H.W. (2018) Secondary Peritonitis: Principles of Diagnosis and Intervention. BMJ, 361, k1407. https://doi.org/10.1136/bmj.k1407

[3] Calandra, T. and Cohen, J. (2005) International Sepsis Forum Definition of Infection in the ICU Consensus Conference. The International Sepsis Forum Consensus Conference on Definitions of Infection in the Intensive Care Unit. Critical Care Medicine, 33, 1538-1548. https://doi.org/10.1097/01.CCM.0000168253.91200.83

[4] Dogra, Y. and Pal, A. (2017) Spontaneous Bacterial Peritonitis during Pregnancy: A Rare Occurrence. Journal of Gynecology and Women's Health, 3, Article ID: 555611. https://doi.org/10.19080/JGWH.2017.03.555611

[5] Le Treut, Y.P. and Houssin, D. (1991) Pathologie Chirurgicale. In: Fagniez, P.L. and Houssin, D., Eds., Chirurgie digestive et thoracique, Tome 2, Éditions Masson, Paris Milan Barcelone, 337-342.

[6] Mohsine, R., Ismaël, F., Lekhal, B., El Faricha, E.H., Errougham, A., Chkoffi, M.R., et al. (1996) Péritonite et grossesse. Médecine du Maghreb, 7, 27-29.

[7] Falindes, A. and Hardy, E. (1997) Illegal Abortion: Consequences for Women's Health and the Health Care System. International Journal of Gynecology \& Obstetrics, 58, 77-83. https://doi.org/10.1016/S0020-7292(97)02860-9

[8] Sokal, R.F. and Rolhf, S.W. (1995) Biometry. 7th Edition, Freeman and Co., San Francisco. 
[9] Harouna, Y.D., Abdou, I., Saidou, B. and Bazira, L. (2001) Les péritonites en milieu tropical: Particularités étiologiques et facteurs pronostiques actuels. A propos de 160 cas. Médecine de Afrique Noire, 48, 103-106.

[10] Ouangre, E., Zida, M., Bonkoungou, P.O., Sanou, A. and Traoré, S.S. (2013) Les péritonites aigues généralisées en milieu rural au Burkina Faso: A propos de 221 cas. Revue CAMES, 1, 75-79.

[11] Kanté, L., Diakité, I., Togo, A., Dembélé, B.T., Traoré, A., Maïga, A., Samaké, H., Kéita, M., Traoré, I. and Diallo, O. (2013) Péritonites aigues généralisées à l'Hôpital Sominé Dolo de Mopti: Aspects épidémiologique et thérapeutique. Mali Médical, 28, 20-23.

[12] Ngo Nonga, B., Mouafo Tambo, F.F., Ngowe Ngowe, M., Takongmo, S. and Sosso, M.A. (2010) Etiologies des péritonites aiguës généralisées au CHU de Yaoundé. Revue Africaine de Chirurgie et Spécialités, 4, 30-32. https://doi.org/10.4314/racs.v4i7.66378

[13] Iloki, L.H., Zakouloulou-Massala and Gbala-Sapoulou, M.V. (1997) Complications des avortements clandestins: A propos de 221 cas observés au CHU de Brazzaville (Congo). Médecine d'Afrique Noire, 44, 262-264.

[14] Ibrahim, K.A., Papa Saloum, D., Amalou Bocar, N., Aliou Coly, F., Ndyaye, J.M. and Babacar, F. (2016) Péritonite aigue généralisée par perforation utérine post-abortum à propos d'une observation. Pan African Medical Journal, 24, 98-101. https://doi.org/10.11604/pamj.2016.24.98.9307

[15] Takongmo, S., Bimam, F., Simeu, C.H., Ngassa, P., Kouam, L. and Mulngu, E. (2000) Aspect thérapeutique des péritonites génitales au CHU de Yaoundé. Medecine d Afrique Noire, 47,19-21.

[16] Coffman, C. (2001) Bowel Injury as a Complication of Induced Abortion: A Case Report and Literature Review. The American Surgeon, 67, 924-926.

[17] Jhobta, R.S., Attri, A.K. and Jhobta, A. (2007) Bowel Injury Following Induced Abortion. International Journal of Gynecology \& Obstetrics, 96, 24-26. https://doi.org/10.1016/j.ijgo.2006.07.010

[18] Hilal, G.F., Thiam, L.P., Ndiaye, P.I. and Diouf, El. (2014) Une complication grave des avortements provoqués clandestins: Le choc septique secondaire à une péritonite par perforation caecale avec rétention d'instruments. RAMUR, 19, 88-92.

[19] Kambiss, S.M., Hibbert, M.L., Macedonia, C. and Potter, M.E. (2000) Uterine Perforation Resulting in Bowel Infarction: Sharp Traumatic Bowel and Mesenteric Injury at the Time of Pregnancy Termination. Military Medicine, 165, 81-82. https://doi.org/10.1093/milmed/165.1.81

[20] Oludiran, O.O. and Okonofua, F.E. (2003) Morbidity and Mortality from Bowel Injury Secondary to Induced Abortion. African Journal of Reproductive Health, 7, 7-12. https://doi.org/10.2307/3583290

[21] Lebeau, R., Guié, P., Bohoussou, É., Akpa-Bédi, É.S.A., Loukou, Y., Kouassi, J.C. and Anongba, S. (2013) Une complication rare mais grave des avortements provoqués clandestins: L'évisceration iléale per vaginum. Gynécologie Obstétrique \& Fertilité, 41, 193-195. https://doi.org/10.1016/j.gyobfe.2011.11.001

[22] Wright, H.K., Dun, D., Mac Arthur, J.D. and Pelucia, O. (1982) Specific Bit Limited Role of New Imaginy Techniques in Decision Making about Intra-Abdomonal Abcesses. The American Journal of Surgery, 143, 456-459. https://doi.org/10.1016/0002-9610(82)90195-7

[23] Robert, H.G. (1976) Urgences gynécologiques. In: Detrie, P.H., Ed., Chirurgie d urgence, 
Masson, Paris, 71-77.

[24] Aulagner, G., Foumier, B., Prudhomme, B., et al. (1981) Perforation utérine et sigmoïdienne après interruption volontaire de grossesse par aspiration. Journal de Chirurgie, 118, 339-341.

[25] Bourgoin, A., Leone, M. and Martin, C. (2004) Prise en charge thérapeutique des péritonites. Médecine et Maladies Infectieuses, 34, 183-195. https://doi.org/10.1016/j.medmal.2004.03.002

[26] Savoie, P.H., Peycru, T., Mingoutaud, L.A., Sow, N., Biance, G., Pauleau, L., Garcia, P. and Farthoua, T. (2011) Péritonites primitives en Afrique subsaharienne: A propos de 15 cas. Annals of African Medicine, 5, 213-219.

[27] Strauss, E. and Cal, Y.W.R. (2006) Spontaneous Bacterial Peritonitis: A Therapeutic Update. Expert Review of Anti-Infective Therapy, 4, 249-260. https://doi.org/10.1586/14787210.4.2.249

[28] Sheerta, L. and Runyonba, B. (2005) Spontaneous Bacterial Peritonitis. Digestive Diseases, 23, 39-46. https://doi.org/10.1159/000084724

[29] Caruntufa, H. and Bene, A.L. (2006) Spontaneous Bacterial Peritonitis: Pathogenesis, Diagnosis, Treatment. Journal of Gastrointestinal and Liver Diseases, 15, 516. 